\title{
Strength and Fracture Resistance of Amorphous Diamond-Like Carbon Films for MEMS
}

\author{
K. N. Jonnalagadda ${ }^{1}$ and I. Chasiotis ${ }^{2}$ \\ ${ }^{1}$ Mechanical Engineering, Johns Hopkins University, Baltimore, MD 21218, USA \\ ${ }^{2}$ Aerospace Engineering, University of Illinois at Urbana-Champaign, Urbana, IL 61801, USA \\ Correspondence should be addressed to I. Chasiotis, chasioti@uiuc.edu \\ Received 6 December 2008; Accepted 22 May 2009 \\ Recommended by Rakesh Joshi
}

The mechanical strength and mixed mode I/II fracture toughness of hydrogen-free tetrahedral amorphous diamond-like carbon (ta-C) films, grown by pulsed laser deposition, are discussed in connection to material flaws and its microstructure. The failure properties of ta-C were obtained from films with thicknesses $0.5-3 \mu \mathrm{m}$ and specimen widths $10-20 \mu \mathrm{m}$. The smallest test samples with $10 \mu \mathrm{m}$ gage section averaged a strength of $7.3 \pm 1.2 \mathrm{GPa}$, while the strength of $20-\mu \mathrm{m}$ specimens with thicknesses $0.5-$ $3 \mu \mathrm{m}$ varied between 2.2-5.7 GPa. The scaling of the mechanical strength with specimen thickness and dimensions was owed to deposition-induced surface flaws, and, only in the smallest specimens, RIE patterning generated specimen sidewall flaws. The mode I fracture toughness of ta-C films is $K_{I c}=4.4 \pm 0.4 \mathrm{MPa} \sqrt{\mathrm{m}}$, while the results from mixed mode I/II fracture experiments with cracks arbitrarily oriented in the plane of the film compared very well with theoretical predictions.

Copyright ( $) 2009$ K. N. Jonnalagadda and I. Chasiotis. This is an open access article distributed under the Creative Commons Attribution License, which permits unrestricted use, distribution, and reproduction in any medium, provided the original work is properly cited.

\section{Introduction}

The application of novel structural materials, such as nanocrystalline diamond [1] and amorphous diamond like carbon [2], in micro/nano-electromechanical systems (MEMS/ NEMS) has increased in the recent years due to their advantageous mechanical and tribological properties. In order to expedite the insertion of these thin film materials in MEMS applications, thorough understanding of their mechanical behavior is required. In this regard, several experimental methods have been developed to measure the elastic and failure properties of materials for use in MEMS devices. A thorough literature review is provided in [3].

In this paper, previously reported and new results from toughness and mechanical strength experiments are presented in order to obtain further understanding of the reliability of hydrogen-free tetrahedral amorphous diamondlike carbon (ta-C) manufactured at the Sandia National Laboratories. Results from mixed mode stress intensity factors, $K_{I}$ and $K_{I I}$, are presented and discussed in terms of material fabrication, specimen size effects, and residual stress gradients.

\section{Experiments}

2.1. Specimen Preparation. The ta-C specimens were manufactured at the Sandia National Laboratories [4] from a graphite target by pulsed laser deposition (PLD). They were composed of $70-80 \% \mathrm{sp}^{3}$ and $20-30 \% \mathrm{sp}^{2}$ carbon. Their composition depended on the laser fluence, which was $>25 \mathrm{~J}$. The as-deposited ta-C consisted of uniformly distributed $\mathrm{sp}^{2}$ and $\mathrm{sp}^{3}$ phases [5] but it has been reported that small clusters of $\mathrm{sp}^{2}$ phase form after thermal annealing, which are of the order of $1-3 \mathrm{~nm}$ [6]. During roomtemperature deposition, subplantation of accelerated carbon atoms towards the substrate caused residual stresses of 6$12 \mathrm{GPa}$ in as-deposited films [7]. These stresses were relieved by annealing the samples at $600^{\circ} \mathrm{C}$ for a few minutes in Ar, which reduced the stresses to less than $1 \mathrm{GPa}$. The high compressive stresses during deposition can cause film delamination from its substrate and, therefore, a maximum single layer thickness of about $200 \mathrm{~nm}$ is permitted. Thicker films can be deposited in the form of multiple layers with annealing performed after each deposition of each layer. In order to fabricate MEMS devices from ta-C, the films are 


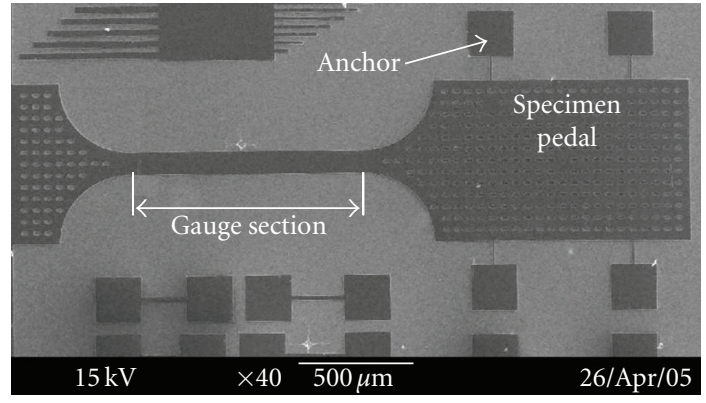

Figure 1: SEM micrograph of a ta-C microscale tension dog-bone specimen. The specimen pedal is used to grip the specimen and to apply a tensile load to the gauge section.

patterned by using aluminum mask and oxygen plasma [4]. Figure 1 shows the top view of a ta-C specimen anchored to a substrate by tethers which are connected to the square pads. The specimens for fracture mechanics studies were $100 \mu \mathrm{m}$ wide, $1 \mu \mathrm{m}$ thick, and $1000 \mu \mathrm{m}$ long. The specimens used for fracture strength experiments were $20 \mu \mathrm{m}$ wide, 500, or $1000 \mu \mathrm{m}$ in length and $0.5-3.0 \mu \mathrm{m}$ in thickness. Four different thicknesses were used to establish the effect of processing parameters on the mechanical failure of ta-C films.

The elastic properties of these films were presented in previous publications. The average elastic modulus for all thicknesses, as measured by uniaxial tension specimens and the AFM/DIC method [8], was $843 \pm 54 \mathrm{GPa}$ and their Poisson's ratio was $0.17 \pm 0.03[9,10]$.

2.2. Preparation of Mixed Mode I/II Fracture Specimens. The procedure for creating oblique precracks for the mixed-mode fracture experiments is similar to the one employed for the mode-I fracture toughness work by the authors before [11]. Pre-cracks were introduced in the fracture specimens by microindentation as previously reported by the authors $[10,12]$ and first discussed by Keller [13] and Ballarini et al. [14]. A microindent was made next to the edge of unreleased specimens while they were attached on a silicon dioxide sacrificial layer. The radial median crack generated from the indent created a pre-crack in the specimen, as shown in Figure 2. The indenter was suitably rotated to form pre-cracks at various angles with different crack lengths. Specimens with pre-cracks that were straight along their entire length were used in the fracture experiments. The oblique pre-cracks allowed for uniaxial loading in the gauge section and various combinations of tensile and shear stresses at the crack tip.

To reduce the uncertainty in measuring the pre-crack geometry, and consequently the computed stress intensity factors (SIFs), scanning electron microscopy (SEM) micrographs provided the overall orientation of the crack with respect to the edge of the specimen, whereas, AFM images showed the local details of the crack tip. An accuracy of 10 $\mathrm{nm}$ in measuring the pre-crack length and of $1^{\circ}$ or better in the measured pre-crack angle can be achieved by using an AFM. The crack lengths were in the range of $12-29 \mu \mathrm{m}$ and the crack angles varied from $7^{\circ}-38^{\circ}$. Film thickness measurements were performed by a surface profilometer and an SEM.

After the geometry measurements, the specimens were released from their substrate by wet etching the $\mathrm{SiO}_{2}$ sacrificial layer in $49 \mathrm{wt} . \% \mathrm{HF}$ and by performing $\mathrm{CO}_{2}$ critical point drying (CPD). The same etching procedure was followed to obtain the freestanding tension the specimens for fracture strength measurements. SEM micrographs after specimen release showed no further pre-crack extension, while the pre-cracks "closed," asserting the fact that the precracks were indeed sharp with singular crack tips.

\subsection{Calculation of Strength and Mixed Mode I/II Fracture} Toughness from Experiments. The freestanding specimens were tested in fixed-fixed configuration [12]. An important aspect of these fracture experiments was to ensure that loading was uniform and that no bending moment was applied in the in-plane direction. Loading was accomplished with a PZT actuator (Polytec PI) with a $1 \mathrm{~nm}$ displacement resolution and $\sim 0.5 \%$ linearity. The force applied to the specimens was measured with a load cell (quasistatic) with a resolution of $0.1 \mathrm{mN}$ and $1 \%$ linearity (with respect to its full-scale). Ta-C is brittle, linearly elastic, and because of its insignificant (calculated) process zone, see reference [10], the use of the plane strain assumption at the crack tip is valid in computing the stress intensity factors. The measured stress just before specimen failure is used in the calculations of the fracture strength and the stress intensity factor (SIF).

The majority of the fracture strength measurements were conducted with $20-\mu \mathrm{m}$ wide specimens that had four different thicknesses, $0.5 \mu \mathrm{m}, 1 \mu \mathrm{m}, 2.2 \mu \mathrm{m}$, and $3 \mu \mathrm{m}$, and two different lengths, $500 \mu \mathrm{m}$ and $1000 \mu \mathrm{m}$. The independent variation of the specimen outer surface area and volume, allowed quantifying the specimen size dependence of the measured mechanical strength. The load drop at failure and the cross-sectional area were used to compute the fracture strength. For each specimen thickness and length several experiments were conducted and their average values are reported here plus/minus one standard deviation.

The mixed-mode I/II stress intensity factors, $K_{I}$ and $K_{I I}$, for an oblique edge crack in a $2 \mathrm{D}$ plate under uniaxial tension, see Figure 3, are [15]

$$
\begin{aligned}
K_{I} & =Y_{I} \sigma_{\infty} \sqrt{\pi a} \cos ^{2}(\theta), \\
K_{I I} & =Y_{I I} \sigma_{\infty} \sqrt{\pi a} \sin (\theta) \cos (\theta),
\end{aligned}
$$

where $Y_{I}$ and $Y_{I I}$ are the mode-I and mode-II shape factors, associated with finite width specimen, which depend on the dimensions of the specimen, the crack length, $a$, and the precrack angle, $\theta$.

Due to the nonstandard specimen geometry and load application in our mixed mode fracture experiments, there are no closed form solutions available to calculate $K_{I}$ and $K_{I I}$ directly from boundary (stress) measurements. Instead, a finite element (FE) analysis was conducted to deduce the fracture parameters from our experimental data. Figure 3 shows the boundary conditions used in the FE analysis to extract $K_{I}$ and $K_{I I}$. The specimen length in the model was 


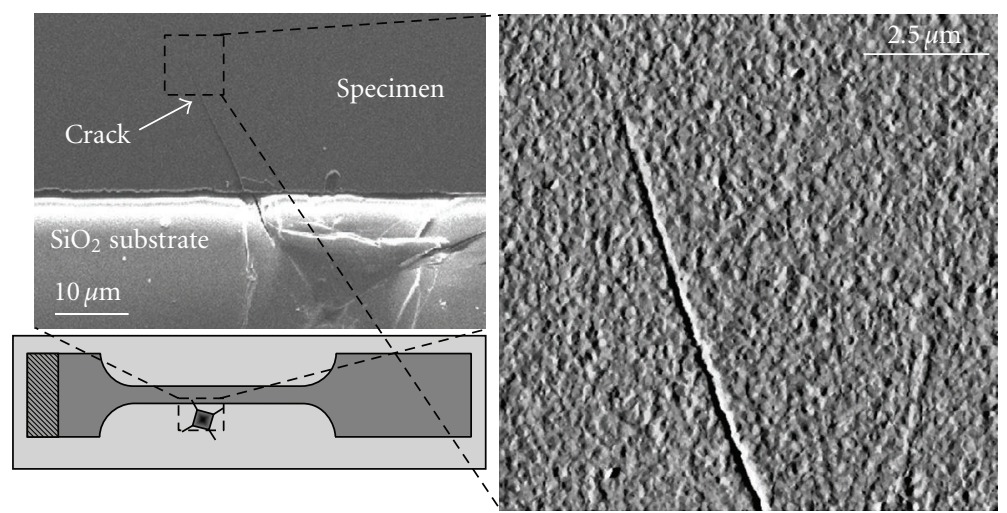

FIGURE 2: (Left) Indent next to a specimen edge and SEM micrograph of a microindent used to generate oblique edge pre-crack in a ta-C specimen. (Right): AFM image of a pre-crack and its tip.

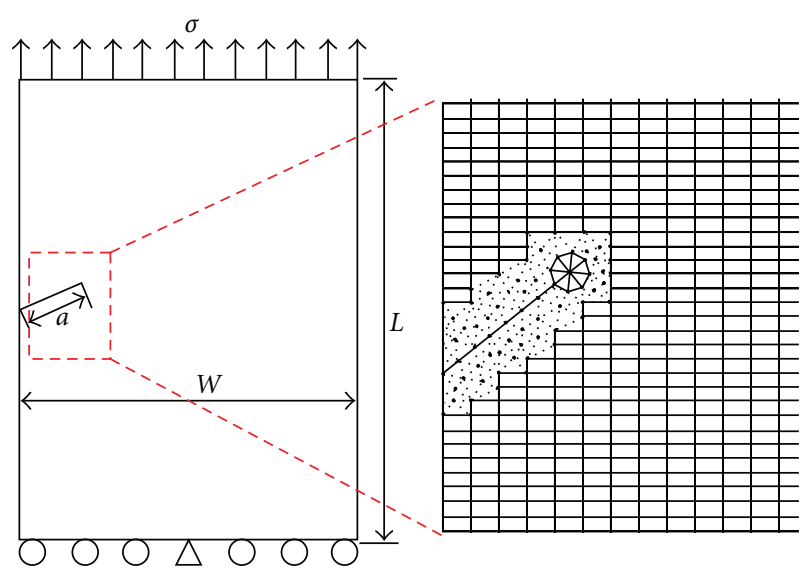

FiguRe 3: Specimen model showing the boundary conditions and the finite element mesh in the vicinity of the crack tip used in numerical calculations of the stress intensity factors.

$L=5 w$. It was verified that the model geometry and its relative dimensions did not bias the computed $K_{I}$ and $K_{I I}$. The deformation fields and the stress intensity factors were calculated by FRANC2DL $[16,17]$. This interactive FE analysis program allows for 2D modeling of cracks in solids and for calculating stress intensity factors via displacement correlation, modified crack closure integral, and J-integral based formulations. The J-integral method gave the most consistent results in our mixed mode stress intensity factor calculations.

The $J$-integral is a non-linear, elastic path independent, integral defined as [18]

$$
J=\lim _{\Gamma \rightarrow 0} \int_{\Gamma}\left[W n_{1}-\sigma_{i j} \frac{\partial u_{i}}{\partial x_{1}} n_{j}\right] d \Gamma
$$

where $W$ is the strain energy density, $\sigma$ is the stress tensor, $n$ is the unit vector normal to the contour $\Gamma$, and $u$ is the displacement vector, as shown in Figure 4(a). For a homogeneous linearly elastic material, $J$ is equal to $G$, the energy release rate.

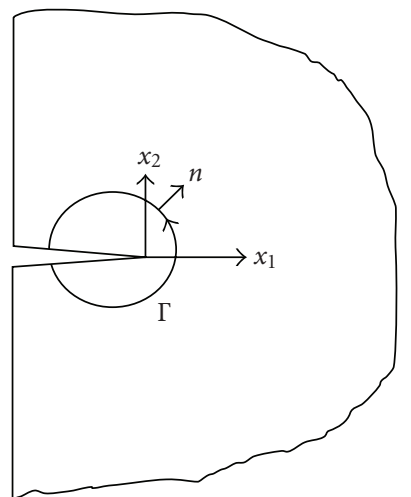

(a)

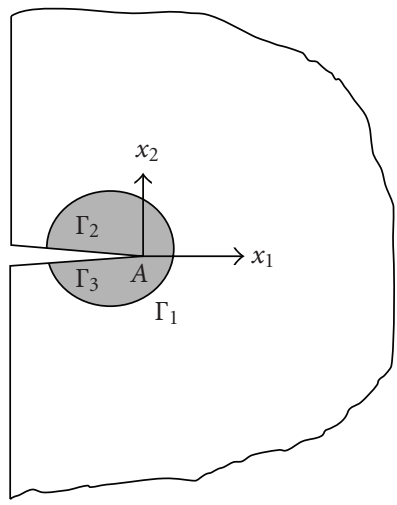

(b)
FIgure 4: (a) Crack tip coordinate system in an infinite body for $J$-integral evaluation and (b) equivalent area domain for $J$-integral evaluation [19].

For this mixed mode plane strain fracture problem, $J$ or $G$ is equal to

$$
J=G=\frac{\left(K_{I}^{2}+K_{I I}^{2}\right)\left(1-v^{2}\right)}{E},
$$

where $E$ is the elastic modulus and $v$ is the Poisson's ratio. This domain integral was later modified by Li et al. [20] into an area integral suitable for finite element calculations, as shown in Figure 4(b). The area form of the integral is [18]

$$
\bar{J}=\int_{A}\left[\sigma_{i j} \frac{\partial u_{i}}{\partial x_{1}}-W \delta_{1 j}\right] \frac{\partial q_{1}}{\partial x_{i}} d A,
$$

where $\delta$ is the Kronecker delta and $q$ is the weight function defined over the domain of integration. The value of $q$ should be such that it is equal to zero at the crack tip and equal to one on the boundary [18]. It is seen that $J$ or $G$ in (3) are a combination of the stress intensity factors, $K_{I}$ and $K_{I I}$, which are separated into different fracture modes via a technique introduced by Ishikawa [19] and Bui [21]. The crack tip displacements were decomposed into their symmetric $\underset{\sim}{\underset{\sim}{u}}$ and antisymmetric $\underset{\sim I}{u}$ components with respect to the crack. 
Similarly, a decomposition of the stress field was obtained and the mode separated $J$-integral values and the plane strain SIFs are computed as

$$
\begin{aligned}
& \bar{J}_{I}=\bar{J}_{I}(\underset{\sim I}{u}, \underset{\sim}{\sigma}) \quad \bar{J}_{I I}=\bar{J}_{I I}(\underset{\sim}{\underset{\sim}{u} \underset{\sim}{\sigma}}), \\
& K_{I}=\sqrt{\frac{E \bar{J}_{I}}{\left(1-v^{2}\right)}} \quad K_{I I}=\sqrt{\frac{E \bar{J}_{I I}}{\left(1-v^{2}\right)}} .
\end{aligned}
$$

Finally, the values of $K_{I}$ and $K_{I I}$ were extracted from the mixed mode fracture experimental data and the $J$-integral technique was implemented in FRANC2DL.

In terms of meshing, 6-node quarter point triangular elements (T6) were employed to capture the crack tip singularity. The mesh was refined around the crack tip until convergence was achieved. The rest of the model was meshed with 8 -node bilinear quad elements. Figure 3 shows the mesh generated for a finite width specimen with an edge crack. For each sample tested a new mesh was generated to accommodate the new crack length and angle. The boundary conditions were set to satisfy the fixed-fixed loading configuration shown in Figure 3. Benchmark fracture problems were solved first and the computed SIFs were compared with those obtained by other methods to ensure the convergence and accuracy of the numerical solution with respect to the mesh density and element size. For instance, the case of a single edge crack in a very large plate was solved and the SIF was compared with the analytical solution [17], and the SIF values computed by Kim and Paulino [22] who used the Mintegral in conjunction with the boundary element method (BEM).

\section{Results and Discussion}

3.1. Mechanical Strength Experiments. Table 1 lists the average tensile strength and its standard deviation as a function of specimen thickness and length [23]. In general, the tensile strength scaled adversely with the film thickness, Figure 5(a), when the specimen length was maintained the same. The thinnest films, $0.5 \mu \mathrm{m}$, did not demonstrate a change in their mechanical strength with the specimen length, which implies that, for small film thicknesses, there is a statistically representative (shown by the decrease in the standard deviation of strength values) surface flaw population in both small and large samples, which could be a combination of top and side wall film surface flaws of small size. Hence, for this film thickness the flaw population in a $20 \times$ $500 \mu \mathrm{m}^{2}$ film area was representative of the flaw distribution in the entire film deposited on the die and, therefore, the value for the mechanical strength of $5.4 \pm 1.2 \mathrm{GPa}$ is representative for the $0.5 \mu \mathrm{m}$ thick ta-C films provided that they are comparable or larger in surface area than the tested specimens. SEM images actually showed randomly distributed small flaws which were of the order of a few nanometers and, potentially, the source of failure where the side-wall specimen ridges. However, the mechanical strength of brittle materials is considered a stochastic property and when stringent reliability requirements are in place then very conservative material proofing approaches are needed [24].
TABle 1: Tensile strength of ta-C as a function of specimen dimensions.

\begin{tabular}{ccc}
\hline Thickness $(\mu \mathrm{m})$ & Length $(\mu \mathrm{m})$ & Tensile Strength $(\mathrm{GPa})$ \\
\hline \multirow{2}{*}{0.5} & 500 & $5.4 \pm 1.2$ \\
& 1000 & $5.7 \pm 0.3$ \\
1.0 & 500 & $5.5 \pm 0.9$ \\
& 1000 & $3.9 \pm 0.7$ \\
2.2 & 500 & $4.3 \pm 1.4$ \\
& 1000 & $3.4 \pm 0.9$ \\
3.0 & 500 & $2.2 \pm 0.5$ \\
& 1000 & $2.3 \pm 0.5$ \\
\hline
\end{tabular}

The same arguments are true for the thicker films, $3.0 \mu \mathrm{m}$, for which, the mechanical strength was independent of the specimen size. SEM images actually showed that the thickest films contained large surface flaws that initiated failure. Again, at this extreme of film thickness, the flaw population in $20 \times 500 \mu \mathrm{m}^{2}$ film area was representative of the flaw distribution in the entire film and, therefore, one may use this value, $2.2 \pm 0.5 \mathrm{GPa}$, as a representative strength for the $3.0 \mu \mathrm{m}$ films. In the thickest films, SEM images showed distributed large and deep flaws, some of which were submicron in size. One can then identify two different flaw populations, both distributed at the film surface/volume, whose size correlates with the film thickness, resulting in an apparent correlation between the specimen volume and its strength, as shown in Figure 5(b). However, this correlation is strongly biased by the strength data for the $3.0-\mu \mathrm{m}$ films, and it does not have general applicability.

On the other hand, the strength of the two medium film thicknesses did vary with the specimen length. In these film thicknesses there was a distribution of small (similar to those in $0.5-\mu \mathrm{m}$ films) and large flaws (similar to those in $3.0-\mu \mathrm{m}$ films). Larger specimens contained larger number of large flaws that reduced the film strength significantly. Therefore, the detrimental flaws were not clearly volumetric (i.e., they still were surface flaws), since it was noticed that no flaws were entirely included inside a specimen; rather, all flaws discernible by an SEM were terminated at the specimen surface. Also, there were no flaws that started at the bottom surface of the films. Therefore, the failure-inducing flaws were attributed to carbon droplets that formed during deposition. As discussed in previous works for other brittle materials for MEMS, the existence of two or more competing flaw populations requires a thorough stress analysis of MEMS components fabricated by these films, since it is the local stress distribution that dictates the active (catastrophic) flaw population [25].

Tests conducted on ta-C fixed-fixed beams by Espinosa et al. [26] made of $0.5 \mu \mathrm{m}$ and $1 \mu \mathrm{m}$ films resulted in strengths between 4.7-5.2 GPa, which agree with our experimental results for the same film thicknesses. Espinosa et al. [26] identified the sidewall roughness as the key factor in failure. The data presented here [25] probed the flaw populations in specimens with different dimensions of top and sidewall surfaces pointing out that the flaws are rather volume related 


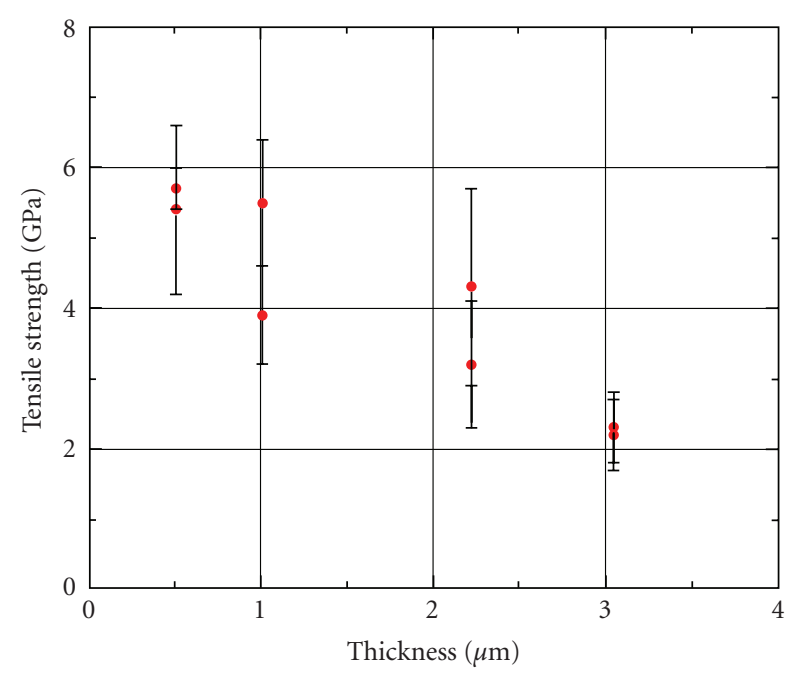

(a)

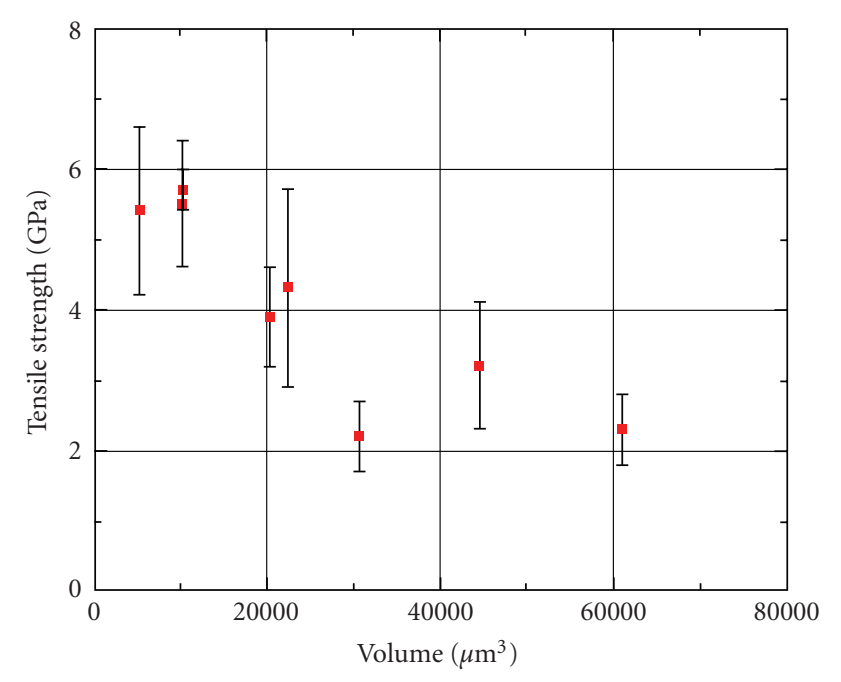

(b)

FIgURE 5: Tensile strength of ta-C as a function of specimen (a) thickness, (b) volume. The error bars correspond to one standard deviation [25].

(i.e., deep top surface flaws that span significant volume inside the specimens.) An appropriate scaling of the failure problem would involve the top surface of the films and would be conducted separately for each film thickness. The sidewall flaws are usually small and have been shown to be the source of failure in very small components. In a previous work by this group [9] $10-\mu \mathrm{m}$ wide and $400-\mu \mathrm{m}$ long ta-C specimens with $1.5 \mu \mathrm{m}$ average thickness provided a tensile strength of $7.3 \pm 1.2 \mathrm{GPa}$, while having the same, or larger, sidewall surface as more than half of the samples listed in Table 1. In the same publication [9] the authors showed that when the effect of top surface flaws was minimized by focusing the stresses to small volumes of very acute notches $(K=27)$ with a radius of curvature of $8 \mu \mathrm{m}$, the local mechanical strength was very consistent averaging $11.4 \pm 0.8 \mathrm{GPa}$. In those cases, failure was indeed the result of the sidewall ridges in the specimen. The last point was supported by a study with microscale polycrystalline silicon specimens [27], which showed that sidewall flaw populations are responsible for failure at locations with high stress concentration factors or small radii of curvature. It should be noted, that the choice of mechanical tests and the geometry and dimensions of brittle specimens can seriously bias the outcome of material strength measurements. The results from such experiments should be analyzed and applied with caution.

3.2. Mixed Mode I/II Fracture Toughness Experiments. The mixed mode I/II fracture experiments were conducted on $1-\mu \mathrm{m}$ thick specimens from two dies, originating in two different fabrication runs. The choice of film thickness was made according to the residual stress gradient in the unreleased films. Prior work showed that $1-\mu \mathrm{m}$ films are the most appropriate to use because they are subject to a minimal effect of residual stress gradients [10]. The experiments conducted by taking this consideration into account resulted

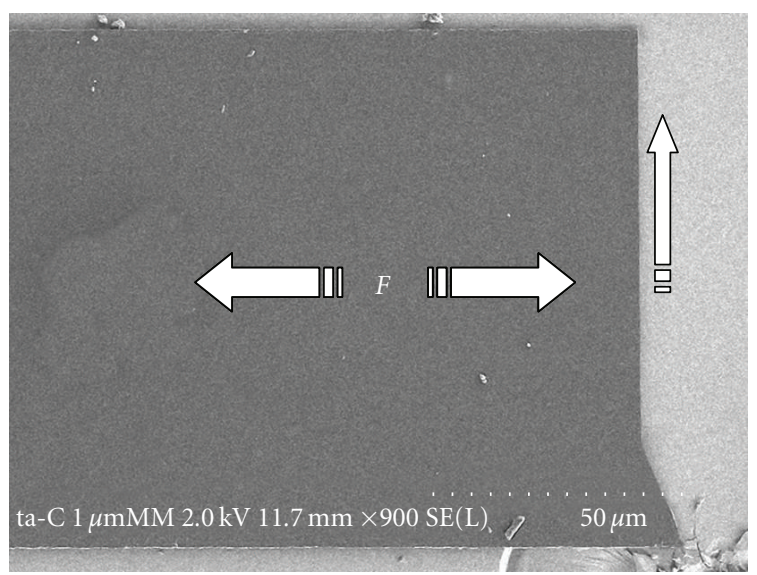

FIGURE 6: SEM micrograph of a fractured ta-C specimen showing the pre-crack (bottom) and the direction of crack propagation pointed by the vertical arrow.

in the expected mode of crack propagation. Figure 6 shows an SEM micrograph of a fractured ta-C specimen with a $30^{\circ}$ pre-crack angle. The fracture path followed a straight line which was normal to the loading direction, indicating properly conducted experiments, as an oblique pre-crack propagates in mode I after an initiation angle and a short smooth transition from the original pre-crack angle.

The normalized stress intensity factors computed by using FRANC2DL, $K_{I} / K_{I C}$, and $K_{I I} / K_{I C}$, where $K_{I C}$ is the mode-I fracture toughness of ta- $C$, are plotted in Figure 7. The experimental uncertainty was less than $3 \%$ and $4 \%$ for $K_{I}$ and $K_{I I}$, respectively. The number next to each datum point is the pre-crack angle. The critical conditions for crack initiation in mixed mode I/II fracture and the direction of crack propagation depend on the local stress field around the crack tip. The two common theoretical criteria [17] for 


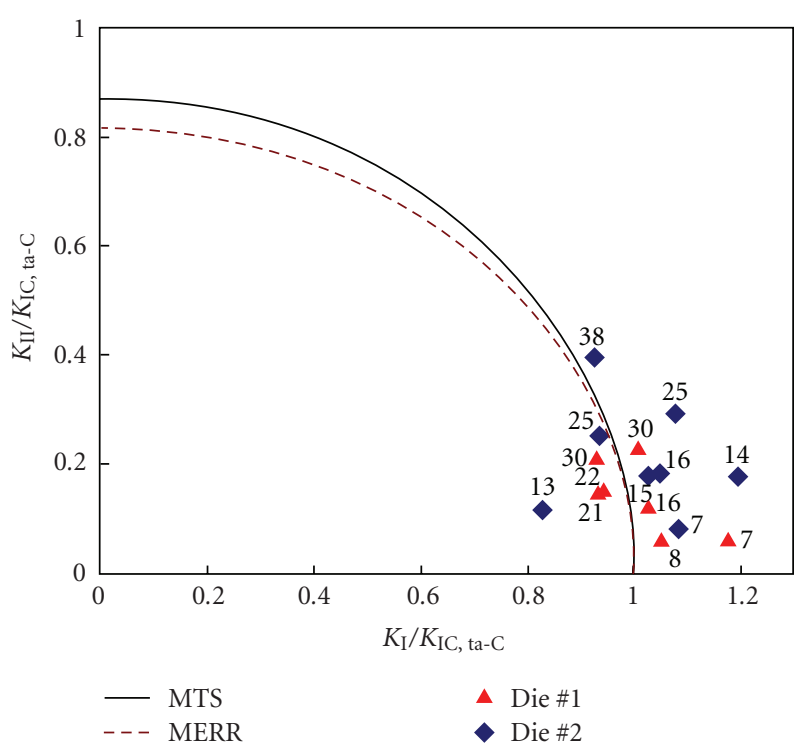

Figure 7: Normalized mixed mode stress intensity factors, $K_{I} / K_{I C}$ versus $K_{I I} / K_{I C}$ for ta-C specimens. The experimental data are compared to predictions by the MERR (dashed line) and the MTS (solid line) criteria. The numbers next to the data points are the pre-crack angles.

critical crack initiation are based on the maximum tensile (or hoop) stress (MTS) [27] and the maximum energy release rate (MERR) [28]. Using these mixed-mode I/II failure criteria the locus of $K_{I} / K_{I C}$ versus $K_{I I} / K_{I C}$ is plotted in Figure 7 with solid and dashed lines, respectively. These two fracture criteria provide an appropriate base for comparison with theory since ta-C is amorphous and can be treated as homogeneous and isotropic at almost all length scales.

The critical stress intensity factor, $K_{I C}$, used to normalize the mixed mode SIFs, was obtained from mode I experiments on specimens from the same die. This way we accounted (to some extent) for the material and gradient stress variations between the two dies. The mode I critical stress intensity factors for the two dies were $3.1 \mathrm{MPa} \sqrt{\mathrm{m}}$ and $3.9 \mathrm{MPa} \sqrt{\mathrm{m}}$ for die number 1 and die number 2, respectively. For each die $K_{I}$ and $K_{I I}$ followed a rather monotonic trend. Without the datum point for the $7^{\circ}$ pre-crack in die number 1 , and the data points for $13^{\circ}$ and $14^{\circ}$ pre-cracks in die number 2, the experimental data fit the theoretical criteria very well. Actually, when compared to mixed mode I/II fracture parameters from amorphous brittle materials at the macroscale, such as PMMA [29], a similar distribution of values is seen, often with a broader distribution of values. The deviation from the MTS and MERR criteria is potentially due the stress gradient in the films before their release from their substrate, which results in a (slight) curvature in the test samples. Upon loading, this curvature is removed resulting in a bending moment at the crack tip. So the difference in $K_{I c}$ values between the two dies is owed to the originally different residual stress gradients in the deposited ta-C and consequently, it does not represent the intrinsic $K_{I c}$ value of the material. For a measurement of the intrinsic $K_{I c}$ of ta- $C$ the reader is referred to reference [10] where it was

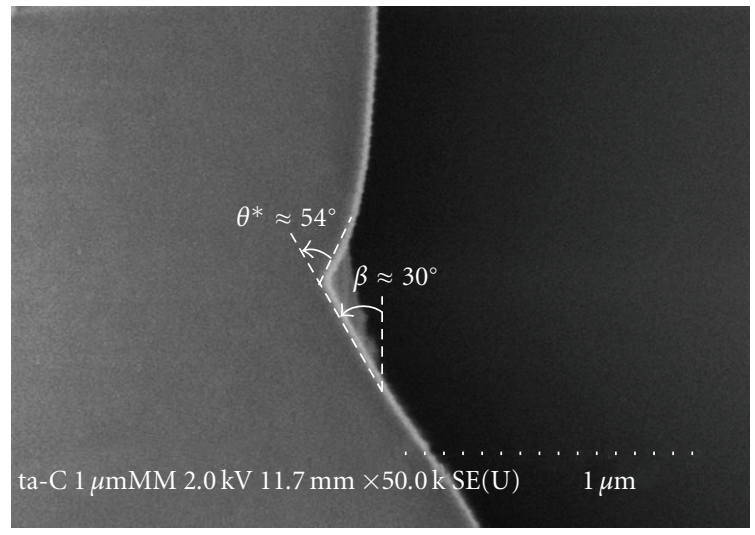

FIGURE 8: SEM micrograph showing the pre-crack, $30^{\circ}$, and the crack initiation, $54^{\circ}$, angles.

found that $K_{I c}=4.4 \pm 0.4 \mathrm{MPa} \sqrt{m}$, which was consistent for ta-C specimens from different dies, which were subject to negligible residual stress gradients before their release.

Finally, Figure 8 is a close up view of the pre-crack tip after fracture. At the onset of fracture, the crack propagated in the direction of the crack initiation angle and finally became normal to the loading direction. For the pre-crack angle $\beta=30^{\circ}$ the crack initiation angle was measured to be $54^{\circ}$. The crack initiation angle is related to the mixed mode stress intensity factors by [17]:

$$
\frac{K_{I I}}{K_{I}}=\tan (\theta)=\frac{-\sin (\beta)}{3 \cos (\beta)-1},
$$

where $\beta$ is the critical crack initiation angle for a given $\theta$. For instance, in this example the predicted initiation angle was $59^{\circ}$, which was close to the experimentally measured value.

\section{Conclusions}

Nanostructured materials applied to MEMS/NEMS can guarantee uniformity in their properties, that is, their effective mechanical behavior is not a function of their dimensions. On the other hand, the failure properties still depend on the size of the MEMS components. Small ta-C material volumes demonstrated high strength; the strength of acute notches with radii of curvature of $8 \mu \mathrm{m}$ was $11.4 \pm$ $0.8 \mathrm{GPa}$, as opposed to the strength of uniform tension taC specimens which was quite lower and with greater scatter in values. Thus, the high mechanical strength is an intrinsic asset of ta- $\mathrm{C}$ but its failure is controlled by submicron flaws that are independent of the material nanostructure and originate in the film deposition and patterning processes. The mechanical strength of the ta- $\mathrm{C}$ specimens tested here did not scale with the specimen volume because of the existence of two flaw populations whose density and severity varied with the film thickness; the thinnest films contained only the smallest flaws while the thickest films had significantly larger flaws. On the other hand, the intermediate film thicknesses shared both flaw types. Therefore, one may apply a Weibull 
analysis to make failure probability predictions only with strength data from films of the same thickness.

As a consequence, the mechanical strength of ta-C, although intrinsically very high, is limited by fabrication hurdles. Hence, it is not an appropriate metric to compare brittle thin film materials in order to make material selections for MEMS devices, since the failure-inducing defects are not intrinsic and very often can be reduced in numbers and size or even be eliminated. In this regard, the fracture toughness is a better measure of the material durability and intrinsic failure consistency since it can probe the average material bond strength (for a brittle material) and its uniformity throughout a thin film. The high fracture toughness of taC, when compared to that of other films for MEMS such as polysilicon [12], places ta-C among the most failure resistant brittle materials. In this paper it was further shown that because of the amorphous nature of ta-C, more complex, and also more realistic cases of fracture, that is, mixed mode I/II fracture can be predicted very well with the aid of brittle fracture criteria derived from continuum mechanics.

\section{Acknowledgments}

The authors gratefully acknowledge the support by the Air Force Office of Scientific Research (AFOSR) through Grants F49620-03-1-0080 and FA9550-09-1-0535 with Doctor B. L. Lee as the program monitor, and by the National Science Foundation (NSF) under Grant CMS 05-15111. The authors thank Doctors T. A. Friedman, and J. P. Sullivan from the Sandia National Laboratories for providing the ta-C specimens for this work.

\section{References}

[1] D. M. Gnien, "Nanocrystalline diamond films," Annual Review of Materials Science, vol. 29, pp. 211-259, 1999.

[2] T. A. Friedmann, K. F. McCarty, J. C. Barbour, M. P. Siegal, and D. C. Dibble, "Thermal stability of amorphous carbon films grown by pulsed laser deposition," Applied Physics Letters, vol. 68, no. 12, pp. 1643-1645, 1996.

[3] I. Chasiotis and W. G. Knauss, "Experimentation at the micron- and submicron scale," in Comprehensive Structural Integrity Vol. 8. Interfacial and Nanoscale Failure, W. Gerberich and W. Yang, Eds., pp. 41-87, Elsevier Science, Oxford, UK, 2003.

[4] J. P. Sullivan, T. A. Friedmann, M. P. de Boer, et al., "Developing a new material for MEMS: amorphous diamond," in Proceedings of the Materials Research Society Symposium, vol. 657, 2001.

[5] M. P. Siegal, J. C. Barbour, P. N. Provencio, D. R. Tallant, and T. A. Friedmann, "Amorphous-tetrahedral diamondlike carbon layered structures resulting from film growth energetics," Applied Physics Letters, vol. 73, no. 6, pp. 759-761, 1998.

[6] J. P. Sullivan, T. A. Friedmann, and A. G. Baca, "Stress relaxation and thermal evolution of film properties in amorphous carbon," Journal of Electronic Materials, vol. 26, no. 9, pp. 1021-1029, 1997.

[7] T. A. Friedmann, J. P. Sullivan, J. A. Knapp, et al., “Thick stressfree amorphous-tetrahedral carbon films with hardness near that of diamond," Applied Physics Letters, vol. 71, no. 26, pp. 3820-3822, 1997.
[8] I. Chasiotis and W. G. Knauss, "A new microtensile tester for the study of MEMS materials with the aid of atomic force microscopy," Experimental Mechanics, vol. 42, no. 1, pp. 5157, 2002.

[9] S. Cho, I. Chasiotis, T. A. Friedmann, and J. P. Sullivan, "Young's modulus, Poisson's ratio and failure properties of tetrahedral amorphous diamond-like carbon for MEMS devices," Journal of Micromechanics and Microengineering, vol. 15, no. 4, pp. 728-735, 2005.

[10] K. Jonnalagadda, S. W. Cho, I. Chasiotis, T. Friedmann, and J. Sullivan, "Effect of intrinsic stress gradient on the effective mode-I fracture toughness of amorphous diamondlike carbon films for MEMS," Journal of the Mechanics and Physics of Solids, vol. 56, no. 2, pp. 388-401, 2008.

[11] S. W. Cho, K. Jonnalagadda, and I. Chasiotis, "Mode I and mixed mode fracture of polysilicon for MEMS," Fatigue and Fracture of Engineering Materials and Structures, vol. 30, no. 1, pp. 21-31, 2007.

[12] I. Chasiotis, S. W. Cho, and K. Jonnalagadda, "Fracture toughness and subcritical crack growth in polycrystalline silicon," Journal of Applied Mechanics, vol. 73, no. 5, pp. 714722, 2006.

[13] C. Keller, Microfabricated High Aspect Ratio Silicon Flexures, MEMS Precision Instruments, El Cerrito, Calif, USA, 1998.

[14] R. Ballarini, R. L. Mullen, Y. Yin, H. Kahn, S. Stemmer, and A. H. Heuer, "The fracture toughness of polysilicon microdevices: a first report," Journal of Materials Research, vol. 12, no. 4, pp. 915-922, 1997.

[15] T. L. Anderson, Fracture Mechanics, CRC Press, Boston, Mass, USA, 2nd edition, 1995.

[16] A. R. Ingraffea and P. A. Wawrzynek, "Finite element methods for linear elastic fracture mechanics," in Comprehensive Structural Integrity, R. de Borst and H. Mang, Eds., Elsevier Science, Oxford, UK, 2003.

[17] FRANC2DL Version 2.2, http://www.cfg.cornell.edu/software/ franc2dl.htm.

[18] J. R. Rice, "A path independent integral and the approximate analysis of strain concentration by notches and cracks," Journal of Applied Mechanics, vol. 35, pp. 379-386, 1968.

[19] H. Ishikawa, "A finite element analysis of stress intensity factors for combined tensile and shear loading by only a virtual crack extension," International Journal of Fracture, vol. 16, no. 5, pp. R243-R246, 1980.

[20] F. Z. Li, C. F. Shih, and A. Needleman, "A comparison of methods for calculating energy release rates," Engineering Fracture Mechanics, vol. 21, no. 2, pp. 405-421, 1985.

[21] H. D. Bui, "Associated path independent J-integrals for separating mixed modes," Journal of the Mechanics and Physics of Solids, vol. 31, no. 6, pp. 439-448, 1983.

[22] J.-H. Kim and G. H. Paulino, "T-stress, mixed-mode stress intensity factors, and crack initiation angles in functionally graded materials: a unified approach using the interaction integral method," Computer Methods in Applied Mechanics and Engineering, vol. 192, no. 11-12, pp. 1463-1494, 2003.

[23] S. W. Cho, Nanoscale deformation and fracture mechanics of polycrystalline silicon and diamond-like carbon for MEMS by the AFM/DIC method, Ph.D. thesis, University of Virginia, 2008.

[24] B. L. Boyce, R. Ballarini, and I. Chasiotis, "An argument for proof testing brittle microsystems in high-reliability applications," Journal of Micromechanics and Microengineering, vol. 18 , no. 11, pp. 117001-117004, 2008. 
[25] A. McCarty and I. Chasiotis, "Description of brittle failure of non-uniform MEMS geometries," Thin Solid Films, vol. 515, no. 6, pp. 3267-3276, 2007.

[26] H. D. Espinosa, B. Peng, N. Moldovan, et al., "Elasticity, strength, and toughness of single crystal silicon carbide, ultrananocrystalline diamond, and hydrogen-free tetrahedral amorphous carbon," Applied Physics Letters, vol. 89, no. 7, pp. $1-3,2006$.

[27] F. Erdogan and G. C. Sih, "On the crack extension in plates under plane loading and transverse shear," Journal of Basic Engineering, vol. 85, pp. 519-527, 1963.

[28] C. H. Wu, "Maximum-energy-release-rate criterion applied to a tension-compression specimen with crack," Journal of Elasticity, vol. 8, no. 3, pp. 235-257, 1978.

[29] R. V. Mahajan and K. Ravi-Chandar, "An experimental investigation of mixed-mode fracture," International Journal of Fracture, vol. 41, no. 4, pp. 235-252, 1989. 

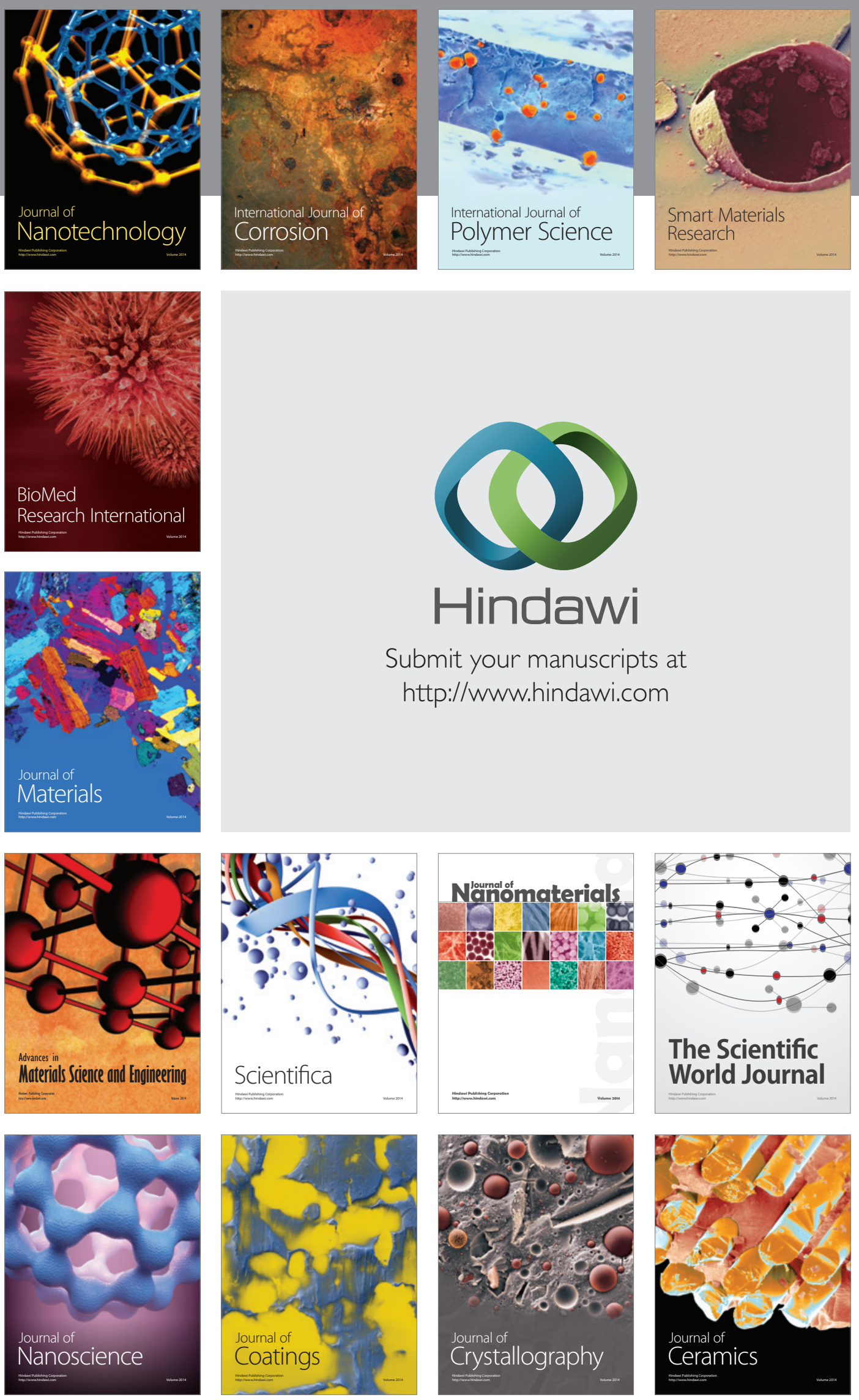

The Scientific World Journal

Submit your manuscripts at

http://www.hindawi.com

\section{World Journal}

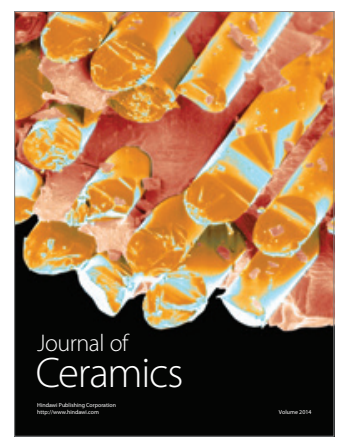

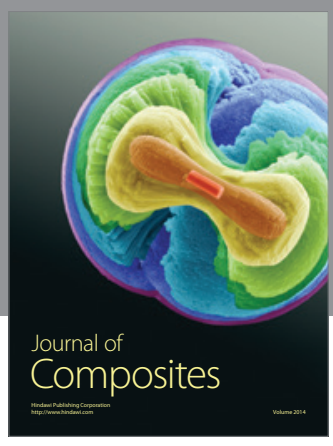
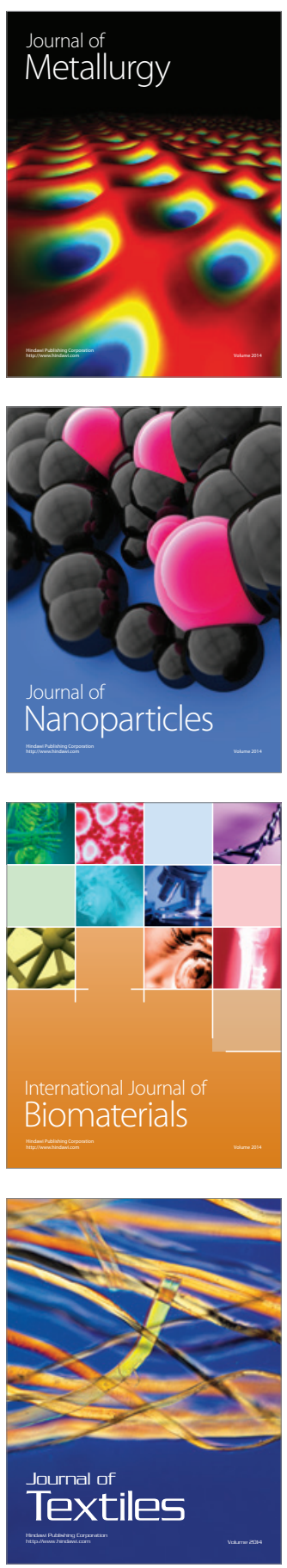